\title{
Left Axis Deviation in Electrocardiogram with Normal QRS Duration in Ambulatory Adults without Cardiac Symptoms: A Possible Marker of Glucose Intolerance
}

\author{
Amar Paudyal, ${ }^{1}$ Madhur Dev Bhattarai, ${ }^{1}$ Buddha Bahadur Karki, ${ }^{1}$ Manil R Bajracharya, ${ }^{1}$ Alark D Rajouria, ${ }^{1}$ Amita \\ Pradhan ${ }^{2}$ \\ 'National Academy of Medical Sciences, Bir Hospital, Kathmandu, ${ }^{2}$ KIST Medical College, Kathmandu, Nepal.
}

\section{ABSTRACT}

Introduction: We are increasingly noticing isolated left axis deviation in electrocardiogram in younger people with diabetes without obvious heart disease and association of LAD with glucose intolerance has not been explicitly raised before. We planned a study of ambulatory adults with borderline $\left(0^{\circ}\right.$ to $\left.-30^{\circ}\right)$ and moderate-to-marked $\left(<-30^{\circ}\right.$ to $\left.-90^{\circ}\right)$ LAD looking into their possible association with glucose intolerance with fasting plasma glucose $(\mathrm{FPG}) \geq 100 \mathrm{mg} / \mathrm{dL}$.

Methods: We consecutively enrolled adults aged 30 or more, with electrocardiogram normal duration QRS axis between $0^{\circ}$ to $-90^{\circ}$, without cardiac symptoms, not on any medication, attending outdoor-clinics for health checkup.

Results: Out of 100 participants enrolled, about 90\% were aged between 30 and 60 and $47 \%$ had borderline and 53\% moderate-to-marked LAD. Moderate-to-marked LAD group had higher frequencies of abnormal blood pressure, FPG, and lipids than borderline LAD group even after conditioning effects of age and sex $(\mathrm{P} \leq 0.03)$ and of FPG after conditioning effects of BP $(\mathrm{P}=0.02)$. The frequencies of glucose intolerance were $48.9 \%$ even in borderline LAD with $84.9 \%$ in moderate-tomarked LAD group. In moderate-to-marked LAD group mean values of BP, FPG, and lipid profiles were higher $(\mathrm{P}<0.001)$ and abnormal. In borderline LAD group though mean BP and lipid values were normal, FPG was impaired.

Conclusions: Impaired mean FPG values and high frequencies of glucose intolerance in both borderline LAD group with normal BP and moderate-to-marked LAD group with conditioning of effects of BP in relatively younger ambulatory adults without cardiac symptoms indicate possible association between LAD and glucose intolerance.

Keywords: diabetes; ECG; glucose intolerance; left axis deviation.

\section{INTRODUCTION}

Despite different cardiac causes, the finding of isolated left axis deviation (LAD) in electrocardiogram (ECG) is in general of not much clinical significance. ${ }^{1,2}$ LAD is relatively common with advancing age even in the absence of clinically overt heart disease and rare during early adult years. ${ }^{2-15}$ However we are increasingly noticing LAD in younger people with diabetes without obvious heart disease. In reports of different findings in ECG of varied populations, plasma glucose estimation was mostly not done, ${ }^{3,5,7-14}$ and in a few studies showing

Correspondence: Dr. Madhur Dev Bhattarai, National Academy of Medical Sciences, Bir Hospital, Kathmandu, Nepal. Email: mdb@ ntc.net.np, Phone: +977-1-4434281. 
Paudyal et al. Left Axis Deviation in Electrocardiogram with Normal QRS Duration in Ambulatory Adults Without Cardiac Symptoms...

some association of LAD with hyperglycemia, the LAD was attributed to the associated heart disease. ${ }^{6,15,16}$ There is hardly any study of LAD itself correlating with glucose intolerance and the association of LAD with glucose intolerance has not been explicitly raised before. Several groups and editorials currently advise against routine screening or risk assessment with resting ECG in asymptomatic patients, as the current evidence is insufficient to assess the balance of benefits and harms of screening with resting or exercise ECG. ${ }^{17-19}$ In these backgrounds, if there is any association between LAD and glucose intolerance it will open a new horizon to consider.

The limits for ECG frontal plane axis deviation are considered necessarily arbitrary. ${ }^{1,20}$ An axis of $-30^{\circ}$ to $-90^{\circ}$ is often accepted as LAD. ${ }^{21}$ However an axis of $0^{\circ}$ to $-90^{\circ}$ is also regarded as LAD with $0^{\circ}$ to $-30^{\circ}$ as slight and $-30^{\circ}$ to $-90^{\circ}$ as marked $L A D, 22$ and $-30^{\circ}$ as borderline $L A D^{23}$. Further $-30^{\circ}$ to $-45^{\circ}$ is now considered as moderate $L A D$ and $-45^{\circ}$ to $-90^{\circ}$ as marked LAD ${ }^{24}$.We are reporting an exploratory study of ambulatory individuals without cardiac symptoms with borderline $\left(0^{\circ}\right.$ to $\left.-30^{\circ}\right)$ and moderate-to-marked $\left(<-30^{\circ}\right.$ to $\left.-90^{\circ}\right)$ LAD looking into their possible association with glucose intolerance as measured by fasting plasma glucose (FPG).

\section{METHODS}

This is a cross-sectional study conducted in the affiliated hospital of National Academy of Medical Sciences (NAMS) in Kathmandu, Nepal. People aged 30 years or more with ECG frontal plane QRS axis between $0^{\circ}$ to $-90^{\circ}$ with normal QRS duration without cardiac symptoms, like chest pain, dyspnea, palpitation, syncope and leg-swelling and not on any medication attending outdoor-clinics for health checkup were enrolled consecutively from December 2006 to December 2007. We compared FPG along with age, sex, body mass index, blood pressure (BP), lipid profile and urine albumin of the borderline LAD with those of the moderate-to-marked LAD group. Women with pregnancy were excluded. Participation was voluntary and consent was taken. The study was approved by Institutional Review Board of NAMS.
The resting 12 lead ECG was taken. The computer reports of the QRS duration and axis were confirmed by inspection of the ECG supplemented by plotting the net amplitude and directions of the QRS complex in any two standard limb leads as required. ${ }^{25} \mathrm{BP}$ was measured after at least five minute of rest, on the right arm with the subject seated. ${ }^{26}$ Urine was collected for albumin examination by dipstick method. Fasting blood specimens were taken in the morning for glucose and lipid estimation. FPG was measured by glucose oxidase method and $\geq 100 \mathrm{mg} / \mathrm{dL}$ was considered as glucose intolerance as recommended by the American Diabetes Association. ${ }^{27}$

Analysis was carried out using standard statistical software SPSS 11.5. Association between categorical variables was assessed by $\mathrm{X} 2$ test. Mantel Haenszel statistics was used to assess the association/s conditioning the third variable. To compare the means in independent groups, independent t-test was used. Test for single proportion was used to compare the frequency of glucose intolerance in the study with prevalence of the related general population.

\section{RESULTS}

Out of consecutive 100 participants enrolled, about $90 \%$ were aged between 30 and 60 years and nearly $60 \%$ men; $47 \%$ had borderline and $53 \%$ had moderateto-marked LAD (Table 1). Moderate-to-marked LAD group had significantly higher frequency of older age, male sex, high BP, high FPG, abnormal lipids and albuminuria than borderline $L A D$ group $(P \leq 0.003)$. After conditioning the effects of age and sex, the frequency of glucose intolerance, high BP and lipid abnormalities were significantly higher in moderateto-marked LAD group ( $\mathrm{P} \leq 0.03$, Table 1$)$. Even after conditioning the effects of $\mathrm{BP}$, the frequency of glucose intolerance was higher in the moderate-to-marked LAD group $(P=0.02)$. However in contrast to other abnormalities, the frequencies of glucose intolerance were higher $(48.9 \%)$ even in borderline LAD group with $84.9 \%$ in moderate-to-marked LAD and $68 \%$ in the total participants (Table 1). In moderate-to-marked LAD group, mean (SD) values of BP, FPG, and lipid profiles were higher $(p<0.001)$ and abnormal (Table 2$)$. In borderline LAD group, though the mean (SD) values of BP and lipid profiles were normal, FPG was 101.0 (18.3) $\mathrm{mg} / \mathrm{dL}$ in the glucose intolerance range. 
Paudyal et al. Left Axis Deviation in Electrocardiogram with Normal QRS Duration in Ambulatory Adults Without Cardiac Symptoms...

\begin{tabular}{|c|c|c|c|c|c|c|}
\hline Characteristics & & $\begin{array}{c}\text { Borderline LAD } \\
\text { Group } \\
\text { (n = 47) }\end{array}$ & $\begin{array}{l}\text { Moderate-to- } \\
\text { Marked LAD Group } \\
\quad(n=53)\end{array}$ & $\begin{array}{c}P \\
\text { value }\end{array}$ & $\begin{array}{l}\text { Sex con- } \\
\text { ditioned } P \\
\text { value }\end{array}$ & $\begin{array}{l}\text { Age Con- } \\
\text { ditioned P } \\
\quad \text { value }\end{array}$ \\
\hline \multirow[t]{2}{*}{ Age groups, y } & $30-<45$ & 34 & 4 & $<0.001$ & $<0.001$ & \\
\hline & $\geq 45$ & 13 & 49 & & & \\
\hline \multirow[t]{2}{*}{ Sex } & Female & 26 & 13 & 0.002 & & 0.01 \\
\hline & Male & 21 & 40 & & & \\
\hline \multirow[t]{5}{*}{ BMI, kg/m² } & $<18.5$ & 2 & 3 & 0.610 & & \\
\hline & $18.5-22.9$ & 22 & 24 & & & \\
\hline & $23-24.9$ & 17 & 14 & & & \\
\hline & $25-29.9$ & 6 & 11 & & & \\
\hline & $\geq 30$ & 0 & 1 & & & \\
\hline \multirow[t]{4}{*}{$\mathrm{BP}, \mathrm{mm} \mathrm{Hg}$} & $<120 / 80$ & 26 & 0 & $<0.001$ & $<0.001^{*}$ & $<0.001^{*}$ \\
\hline & $\begin{array}{l}120 / 80- \\
139 / 89\end{array}$ & 15 & 4 & & & \\
\hline & $\begin{array}{l}140 / 90- \\
159 / 99\end{array}$ & 6 & 30 & & & \\
\hline & $\geq 160 / 100$ & 0 & 19 & & & \\
\hline \multirow[t]{2}{*}{ Urine albumin } & Nil & 38 & 28 & 0.003 & 0.003 & 0.12 \\
\hline & Present & 9 & 25 & & & \\
\hline \multirow[t]{2}{*}{$\begin{array}{l}\text { Fasting plasma } \\
\text { glucose, mg/dL }\end{array}$} & $<100$ & 24 & 8 & $<0.001$ & 0.001 & 0.03 \\
\hline & $\geq 100$ & 23 & 45 & & & \\
\hline \multirow[t]{2}{*}{$\begin{array}{l}\text { Total choles- } \\
\text { terol, mg/dL }\end{array}$} & $<250$ & 42 & 20 & $<0.001$ & $<0.001$ & $<0.01$ \\
\hline & $\geq 250$ & 5 & 33 & & & \\
\hline \multirow[t]{2}{*}{$\begin{array}{l}\text { LDL cholesterol, } \\
\mathrm{mg} / \mathrm{dL}\end{array}$} & $<150$ & 45 & 31 & $<0.001$ & $<0.001$ & 0.008 \\
\hline & $\geq 150$ & 2 & 22 & & & \\
\hline \multirow[t]{2}{*}{$\begin{array}{l}\text { HDL choles- } \\
\text { terol, mg/dL }\end{array}$} & $\geq 35$ & 47 & 37 & $<0.001$ & 0.001 & 0.002 \\
\hline & $<35$ & 0 & 16 & & & \\
\hline \multirow[t]{2}{*}{$\mathrm{TG}, \mathrm{mg} / \mathrm{dL}$} & $<200$ & 42 & 20 & $<0.001$ & $<0.001$ & 0.004 \\
\hline & $\geq 200$ & 5 & 33 & & & \\
\hline
\end{tabular}

*For age- and sex-conditioned P value calculationMantel Haenszel statistics was used with BP values $<140 / 90$ and $\geq 140 / 90$.

$\mathrm{BP}=$ blood pressure, $\mathrm{FPG}=$ fasting plasma glucose, $\mathrm{HDL}=$ high density lipoprotein, $\mathrm{LAD}=$ left axis deviation, $\mathrm{LDL}$ =low density lipoprotein, $\mathrm{TG}=$ triglyceride.

\begin{tabular}{|c|c|c|c|}
\hline Characteristics & $\begin{array}{c}\text { Borderline LAD Group ( } \\
=47 \text { ) }\end{array}$ & $\begin{array}{l}\text { Moderate-to-Marked LAD Group } \\
\qquad(\mathrm{n}=53)\end{array}$ & P Values \\
\hline Age, y & $40.3 \pm 8.5$ & $54.5 \pm 6.3$ & $<0.001$ \\
\hline $\mathrm{BMI}, \mathrm{kg} / \mathrm{m}^{2}$ & $22.9 \pm 2.4$ & $23.9 \pm 3.0$ & 0.07 \\
\hline Systolic BP, mm Hg & $122.3 \pm 13.8$ & $154.0 \pm 10.6$ & $<0.001$ \\
\hline Diastolic BP, mm Hg & $78.4 \pm 8.6$ & $96.9 \pm 6.6$ & $<0.001$ \\
\hline FPG, mg/dL & $101.0 \pm 18.3$ & $122.9 \pm 27.5$ & $<0.001$ \\
\hline
\end{tabular}


Paudyal et al. Left Axis Deviation in Electrocardiogram with Normal QRS Duration in Ambulatory Adults Without Cardiac Symptoms...

\begin{tabular}{|llll|} 
Total cholesterol, $\mathrm{mg} / \mathrm{dL}$ & $201.7 \pm 43.9$ & $286.1 \pm 59.7$ & $<0.001$ \\
LDL cholesterol, $\mathrm{mg} / \mathrm{dL}$ & $102.9 \pm 22.1$ & $150.7 \pm 41.0$ & $<0.001$ \\
$\mathrm{HDL}$ cholesterol, $\mathrm{mg} / \mathrm{dL}$ & $57.7 \pm 6.7$ & $41.7 \pm 8.8$ & $<0.001$ \\
Triglyceride, $\mathrm{mg} / \mathrm{dL}$ & $130.7 \pm 53.3$ & $207.3 \pm 53.9$ & $<0.001$ \\
\hline
\end{tabular}

$\mathrm{BP}=$ blood pressure, FPG = fasting plasma glucose, HDL = high density lipoprotein, LAD = left axis deviation, $\mathrm{LDL}$ = low density lipoprotein, TG = triglyceride.

\section{DISCUSSION}

The notable findings in our study are the significantly higher frequency of glucose intolerance in the moderateto-marked LAD group after conditioning the effects of age, sex and BP as well as the mean FPG value in the glucose intolerance range even in the borderline LAD group with normal BP with almost half of its participants having such values. Moreover, the total frequency of $68 \%$ of glucose intolerance detected by FPG alone in the study is much more than the reported age and sex standardized prevalence of $30.5 \%$ of overall glucose intolerance identified by both FPG and twohour post-glucose measurement even in the relatively higher age group of 40 years and above in the urban populations, ${ }^{28}$ where the present study was conducted $(p<0.001)$. In our study, participants mostly aged 30 to 60 years without any cardiac symptoms and not on any medications were enrolled. Thus, as the inclusion of the two major causes of LAD, i.e. old age and cardiac disease, was minimized, the proportion of other possible remaining cause was likely to be magnified. The impaired mean FPG value and high frequency of glucose intolerance even in borderline LAD group with normal BP and in moderate-to-marked LAD group with conditioning of the effects of $\mathrm{BP}$ with relatively younger ambulatory adults without cardiac symptoms indicate possible association between LAD and glucose intolerance.

Fibrosis and sclerodegenerative disorder of the anterior fascicle of left bundle branch (LBB) are postulated to be the cause of LAD in the older population without associated cardiovascular abnormalities. ${ }^{2,11-14,29}$ Fibrotic changes, especially in the basal area of left ventricle, have also frequently been observed in patients with diabetes, even when cardiac involvement is clinically not yet evident. ${ }^{30}$ Chronic hyperglycemia affects various growth factors including fibroblast, collagen, fibronectin, contractile proteins, and extracellular matrix proteins in the body through different mechanisms. ${ }^{31}$ Long thin anterior fascicle of LBB has single source of blood supply making it relatively more vulnerable. ${ }^{2}$ It is interesting to note here that high prevalence of LAD, six-to-nine-fold higher than the control group, in healthy American-Indian Navajo and Apache schoolchildren has been reported, the possible cause of which was considered unexplained. ${ }^{20}$ However, the AmericanIndian population is one of the indigenous groups to be affected in the early phase of the diabetes pandemic, 32 and the high prevalence of diabetes even among younger age group in that population is well known. ${ }^{32,33}$

Further in most ECG reports, including that of people with hyperglycemia, only the presence of LAD, mostly $-30^{\circ}$ to $-90^{\circ}$, is considered, not the different ranges of ORS frontal plane axes. . $^{3,10-13,34}$ The normal mean manifest frontal plane QRS axis ranges from $0^{\circ}$ to $+90^{\circ}$ with most axes in adults being within a narrower range between $+40^{\circ}$ and $+60^{\circ} .{ }^{22}$ The process of gradual shifting of the ECG axis towards left could be associated with the period of exposure to different grades and combination of the related factors like increasing age, glucose level and other factors. Minnesota code was developed in 1960s as a standardized coding system for the ECG to aid the comparability of studies. ${ }^{21}$ However focusing only on its LAD criteria as $-30^{\circ}$ to $-90^{\circ}$ by the studies also appears as one reason of dearth of medical literature about the association of different degrees of QRS axis with possible factors. Because even though the frequency of glucose intolerance in LAD is high as seen in our study, the reciprocal frequency of frank LAD of $-30^{\circ}$ to $-90^{\circ}$ in diabetes may not be obviously high. ${ }^{34}$ Such disproportional frequency of cause and effect in relation to each other is also seen in other conditions. For example, though smoking is responsible for $90 \%$ of chronic obstructive lung disease, the clinical symptoms of respiratory limitations occur in about $15-25 \%$ of smokers. ${ }^{35}$ In our study, the mean FPG value is in the glucose intolerance range even in the borderline $10^{\circ}$ to $\left.-30^{\circ}\right)$ LAD group with normal BP with almost half of its participants having such values. We have extensively reviewed LAD and its association with glucose intolerance. To the best of our knowledge, there is no study of frequency of different grades of axis deviation correlating with glucose intolerance.

Lastly, high BP, lipid abnormalities and albuminuria are also found to be associated with the moderateto-marked LAD in our study. The association of LAD with hypertension is reported by other studies. ${ }^{6,11,12,36}$ Myocardial fibrosis is a well-known key pathological process due to hypertension. ${ }^{37}$ Diabetes and 
hypertension are the two independent chronic systemic causes of nephrosclerosis and proteinuria and similarly could be related to LAD. Hypertension, dyslipidemia and albuminuria are common co-morbidities of glucose intolerance, ${ }^{27}$ and could thus also be related with the increased level of glucose intolerance seen in the moderate-to-marked LAD group in our study.

A number of study limitations merit discussion. There are relatively more men in the study. But as the focus was LAD itself, more men are likely to be selected because LAD is more common in men. ${ }^{4-7,10,15,38,39}$ The additional two-hour post-glucose test could have detected more cases of glucose intolerance and shown stronger association. Glycated hemoglobin was not established for diagnosis of glucose intolerance at that time.Similarly the sample size appears relatively small. However in one year period, it includes adults mostly between 30 and 60 years with LAD itself without cardiac symptoms and not on any medication. In other reports of $L A D$ itself including varied populations even without reporting glucose intolerance, the numbers of participants with LAD were $63^{14}$ and $100^{11}$ in hospital-record, 131 in post-mortem ${ }^{13} 353$ in twelveyears post-mortem ${ }^{10}$ and 413 in eight-years insurancerecord ${ }^{12}$ reports. Our study is hospital-based and some participants may have unexpressed symptoms or concerns for visiting the health institute. The inclusion of different levels of glucose in the two LAD groups along with the available prevalence data of glucose intolerance of the same community provided a sort of control groups for comparison, though the various normal degrees of QRS axis were not studied.

In summary our study indicates that apart from the known association of LAD with cardiac diseases, hypertension, old age and male sex, there is also a possible association between LAD and glucose intolerance. If it is confirmed by further studies, presence of LAD in any individual will indicate the need to assess for glucose intolerance, particularly in women in the reproductive age-group with possibility of pregnancy when insulin resistance is likely to be further increased. Similarly, as glucose intolerance is a major risk factor of CVDs, the presence of LAD may indicate the need to assess further before advising enrollment in any moderate to heavy physical exercise programme or pre-operatively before elective surgery. The knowledge of such association may also prevent unnecessary invasive investigations in asymptomatic people with diabetes, as moderate-tomarked LAD could sometimes be confused with the old inferior wall myocardial infarction.

\section{CONCLUSIONS}

In conclusion, the impaired mean FPG values and high frequencies of glucose intolerance in both borderline LAD group with normal BP and moderate-to-marked LAD group with conditioning of the effects of BP in relatively younger ambulatory adults without cardiac symptoms in our study indicate possible association between LAD and glucose intolerance. We recommend further population-based studies correlating various grades of QRS frontal plane axis of ECG with BP, fasting and post-glucose two-hour plasma glucose, and glycated hemoglobin.

\section{ACKNOWLEDGEMENTS}

We are thankful to the Dean of the National Academy of Medical Sciences for giving us permission to publish the report.

\section{REFERENCES}

1. Goldberger AL. Clinical electrocardiography - A simplified approach. $7^{\text {th }}$ ed. Philadelphia: Mosby; 2007.

2. Perloff JK, Roberts NK, Cabeen WR. Left axis deviation: a reassessment. Circulation. 1979;60(1):12-21.

3. Kitchin AH, Lowther CP, Milne JS. Prevalence of clinical and electrocardiographic evidence of ischaemic heart disease in the older population. Brit Heart J. 1973;35(9):946-53.

4. De Bacquer D, De Baker G, Kornitzer M. Prevalencesof ECG findings in large population based samples of men and women. Heart. 2000;84(6):625-33.

5. Lakkireddy DR, Clark RA, Mohiuddin SM. Electrocardiographic findings in patients $>100$ years of age without clinical evidence of cardiac disease. Am J Cardiol. 2003;92(10):1249-51.
6. Ostrander LD, Brandt RL, Kjelsberg MO, Epstein FH. Electrocardiographic findings among the adult population of a natural community, Tecumseh, Michigan. Circulation. 1965;31:888-98.

7. Hingorani P, Natekar M, Deshmukh S, Karnad DR, Kothari $\mathrm{S}$, Narula D, et al. Morphological abnormalities in baseline ECGs in healthy normal volunteers participating in phase I studies. Indian J Med Res. 2012;135:322-30.

8. Hiss RG, Lamb LE. Electrocardiographic findings in 122,043 individuals. Circulation. 1962;25:947-61.

9. Mason JW, Ramseth DJ, Chanter DO, Moon TE, Goodman DB, Mendzelevski B. Electrocardiographic reference ranges derived from 79,743 ambulatory subjects. J Electrocardiol. 2007;40(3):228-34. 
Paudyal et al. Left Axis Deviation in Electrocardiogram with Normal QRS Duration in Ambulatory Adults Without Cardiac Symptoms...

10. Bahl OP, Walsh TJ, Massie E. Left axis deviation: An electrocardiographic study with post-mortem correlation. Brit Heart J. 1969;31(4):451-6.

11. Grayzel J, Neyshaboori M, Paramw NJ. Left-axis deviation: etiologic factors inone-hundred patients. Am Heart J. 1975;89(4):419-27.

12. Corne RA, Beasmish RE, Rollwagen RL. Significance of left anterior hemiblock. Brit Heart J. 1978;40(5):552-7.

13. Grant RP. Left axis deviation: An electrocardiographicpathological correlation study. Circulation. 1956;14(2):233-49.

14. Das G. Left axis deviation - A spectrum of intraventricular conduction block. Circulation. 1976;53(6):917-9.

15. Ostrander LD. Left axis deviation: Prevalence, associated conditions, and prognosis: An epidemiological study. Ann Intern Med. 1971;75(1):23-8.

16. Uusitupa M, Mustonen J, Siitonen O, Pyorala K. Quantitative electrocardiographic and vectorcardiographic study on newly-diagnosed non-insulin-dependent diabetic and non-diabetic control subjects. Cardiology. 1988;75(1):1-9.

17. Lauer MS. What now with screening electrocardiography? Ann Intern Med. 2011;155(6):395-7.

18. Moyer VA, on behalf of the US Preventive Services Task Force. Screening for coronary heart disease with electrocardiography: US Preventive Services Task Force Recommendation Statement. Ann Intern Med. 2012;157(7):1-7.

19. Greenland P. Should the resting electrocardiogram be ordered as a routine risk assessment test in healthy asymptomatic adults? JAMA. 2012;307(14):1530-1.

20. Ewy GA, Okada RD, Marcus FI, Goldberg SJ, Phibbs BP. Electrocardiographic axis deviation in Navajo and Apache Indians. Chest. 1979;75(1):54-8.

21. Blackburn H, Keys A, Simonson E, Rautharju P, Punsar S. The electrocardiographic in population studies - A classification system. Circulation. 1960;21:1160-75.

22. Schamroth L, Schamroth C. An Introduction to Electrocardiography. 7th ed: Berlin Blackwell Science; 1997.

23. Goldberger AL. Basic principles of ECG analysis. Mirvis DM, Saperia GM, Eds. ECG Tutorial. UpToDate. 2013;21:4.

24. Surawicz B, Childers R, Deal BJ, Gettes LS. AHA/ACCF/HRS Recommendations for the standardization and interpretation of the electrocardiogram part III: intraventricular conduction disturbances. J Am Coll Cardiol. 2009:53(11):976-81.

25. Goldman MJ. Principles of Clinical Electrocardiography. 11th edition. California: Lange Medical Publications / Maruzen Asia; 1982.
26. King H, Minjoot-Pereira G. Diabetes and noncommunicable disease risk factor surveys - A field guide. Geneva: World Health Organization;1999:1-62.

27. American Diabetes Association. Position Statement: Standards of medical care in diabetes - 2013. Diabetes Care. 2013;36(Suppl.1):S11-S66.

28. Shrestha UK, Singh DL, Bhattarai MD. The prevalence of hypertension and diabetes defined by fasting and 2-h plasma glucose criteria in urban Nepal. Diabet Med. 2006,23(10);1130-5.

29. Bradlow BA. The importance of abnormal left axis deviation in life assurance. S Afr Med J. 1973:47(20):877-81.

30. Stern S, Sclerowsky S. The ECG in diabetes mellitus. Circulation. 2009;120(16):1633-6.

31. Powers AC. Diabetes mellitus. In: Longo Dl, Fauci AS, Kasper DL, Hauser SL, Jameson JL, Loscalzo J, eds. Harrison's Principles of Internal Medicine, 18th Ed. New York, NY: McGraw Hill Medical; 2012. p. 2980.

32. Bhattarai MD. Three Patterns of Rising type 2 Diabetes Prevalence in the World: Need to Widen the Concept of Prevention in Individuals into Control in the Community. JNMA. 2009; 48(174):173-9.

33. Gohdes D, Kaufman S, Valway S. Diabetes in American Indians: An overview. Diabetes Care. 1993;16(1):239-43.

34. Pfister R, Cairns R, Erdmann E, Schneider CA on behalf of the PROactive investigators. Prognostic impact of electrocardiographic signs in patients with type 2 diabetes and cardiovascular diseases: results from the PROactive study. Diabet Med. 2011;28(10):1206-12.

35. Burns DM. Nicotine addiction. In: Longo Dl, Fauci AS, Kasper DL, Hauser SL, Jameson JL, Loscalzo J, eds. Harrison's Principles of Internal Medicine, 18th ed. New York, NY: McGraw Hill Medical; 2012. p. 3562.

36. Yano K, Peskoe SM, Rhoads GG, Moore JO, Kagan A. Left axis deviation and left anterior hemiblock among 8,000 Japanese-American men. Am J Cardiol. 1975;35(6):809-15.

37. Cuspidi C, Ciulla M, Zanchetti A. Hypertensive myocardial fibrosis. Nephrol Dial Transplant. 2006;21(1):20-3.

38. Assantachai P, Panchavinnin P, Pisalsarakij D.An electrocardiographic survey of elderly Thai people in the rural community. J Med Assoc Thai. 2002;85(12):1273-9.

39. Bacquer D De, Backer GDe, Kornitzer M, Blackburn. Prognostic value of ECG findings for total cardiovasculatr disease, and coronary heart disease death in men and women. Heart. 1998;80(6):570-7. 